\title{
Endometrial changes in estrogen and progesterone receptor expression during implantation in an oocyte donation program
}

\author{
ELEFTHERIOS KLONOS $^{1}$, PERIKLIS KATOPODIS ${ }^{2}$, EMMANOUIL KARTERIS ${ }^{2}$, \\ EVANGELOS PAPANIKOLAOU $^{1}$, BASIL TARLATZIS ${ }^{3}$ and GEORGE PADOS ${ }^{1,3}$
}

\author{
${ }^{1} 1$ st Department of Obstetrics and Gynecology, Aristotle University of Thessaloniki, School of Medicine, \\ Thessaloniki 541 24, Greece; ${ }^{2}$ Division of Biosciences, College of Health and Life Sciences, Brunel University London, \\ Uxbridge UB8 3PH, UK; ${ }^{3}$ Centre for Assisted Reproduction 'Biogenesis', Thessaloniki 555 35, Greece
}

Received February 27, 2020; Accepted July 15, 2020

DOI: $10.3892 / \mathrm{etm} .2020 .9308$

\begin{abstract}
Implantation is the final and most important stage of embryogenesis and is of paramount importance in achieving a successful pregnancy. Progesterone and estrogen are steroid hormones responsible for the regulation of the implantation window and the current study hypothesised that their receptors may be implicated in women undergoing oocyte donation. A total of 15 women aged 25-32 years old (mean \pm SD, $28.9 \pm 2.89$ ) undergoing oocyte donation were recruited into the present study. Participants underwent ovarian stimulation with gonadotrophin-releasing hormone antagonist and recombinant follicle-stimulating hormone. Endometrial aspiration biopsy was performed on the day of oocyte retrieval and after 5 days (on days 0 and 5, respectively). Endometrial histology and evaluation of estrogen receptor (ER) $\alpha$ and progesterone receptor (PR)-B were performed on days 0 and 5. The ER nodal staining percentage on day 0 was age-associated, with patients aged $<30$ years demonstrating $100 \%$ staining and those aged $>30$ years exhibiting $90 \%$ staining. Pathological staining revealed statistically significant differences between days 0 and 5 following all staining procedures. Wilcoxon signed-rank test resulted in the following P-values, for ER (nodes \% and stromal \%) day 0/5, P=0.0001; for PR (nodes \% and stromal \%) day $0 / 5, \mathrm{P}=0.0001$ and $\mathrm{P}=0.035$, respectively; for $\mathrm{ER}$ (grade nodes and stromal \%) day $0 / 5, \mathrm{P}=0.0001$; and $\mathrm{PR}$ (grade nodes and stromal \%) day $0 / 5 \mathrm{P}=0.0001$ and $\mathrm{P}=0.016$, respectively. Synchronization between blastocyst development and the acquisition of endometrial receptivity is a prerequisite for the success of in vitro fertilisation (IVF). Aside from the recent discovery of molecules that are considered crucial for successful embryo implantation, assessing the functional
\end{abstract}

Correspondence to: Professor George Pados, 1st Department of Obstetrics and Gynecology, Aristotle University of Thessaloniki, School of Medicine, Thessaloniki 541 24, Greece

E-mail: padosgyn@gmail.com

Key words: implantation, endometrial receptivity, in-vitro fertilization, steroid hormone receptors characteristics of the endometrium may offer unique insights into this process, thus improving IVF results.

\section{Introduction}

Implantation is defined as the organized process through which the blastocyst attaches to the endometrium and invades the epithelium to form the placenta. Implantation is directly dependent on the synchronization of the fertilized egg's progression into a blastocyst and the specific differentiation of the endometrium through molecular and cellular changes regulated by agents with an endocrine, paracrine or autocrine activity $(1,2)$. This synchronization occurs over a certain period of time, called the 'window of implantation', and requires a molecular dialogue of sorts between the secretory activity of the endometrium and that of the blastocyst (1-3). Numerous studies have implicated adhesion molecules, extracellular matrix proteins, growth factors, extracellular substrate degradation proteins and pro-inflammatory agents in the implantation process of the blastocyst into the endometrium (4). Collectively these data point towards a complex molecular process, whose underlying mechanisms have not been fully elucidated.

Progesterone and estrogen are the steroid hormones responsible for the regulation of the implantation window. Progesterone induces changes in signalling pathways that lead to the establishment of a receptive endometrium (5). Estrogen receptors (ER) $\alpha$ and $\beta$ and progesterone receptors (PR)-A and -B are expressed in the epithelium and stroma of the human endometrium. ER mediates most of the biological effect of estrogens by interacting with its site-specific DNA and with other coregulatory proteins, while ER and PR signalling during implantation is carried out through paracrine and autocrine factors mediated by growth factors, as well as cytokines (6). Progesterone exerts its effects by activating the canonical PRs to act in a genomic fashion to regulate transcriptional responses of implantation-related genes (5). For example, progesterone drives an increase in the gene expression of integrin $\alpha v \beta 3$ in epithelial cells (7). Integrins are a family of transmembrane binding glycoproteins consisting of two protein subunits $(\alpha$ and $\beta$ ). Integrins function as receptors for extracellular matrix molecules, glycoproteins and other cells, and their concentration in adhesion points leads to the creation of a network of cytoskeletal proteins 
and intracellular signalling $(8,9)$. The importance of these adhesion molecules has been widely studied in mice with blastocysts lacking the $\beta 1$ subunit that fail to implant $(10,11)$.

Other adhesion molecules also play a crucial role in this dialogue underlying the adhesion and attachment of the blastocyst in the adequately prepared endometrium (12). E-cadherin, for example, is critical to the creation and maintenance of blastocyst adhesion ligands (12-14). Since E-cadherin has been found in the trophoblast and endometrium, it has been suggested to participate in the initial adhesion and attachment of the blastocyst during implantation (15).

On the other hand, estrogens exert their-effects by activating primarily the nuclear steroid hormone receptor. ER $\alpha$ appears to be upregulated during the proliferative phase and downregulated during the implantation window, an event driven primarily by progesterone (16). Of note, elevated levels of ER $\alpha$ during implantation were associated with a decrease in $\beta 3$ integrin expression in patients with polycystic ovarian syndrome and endometriosis (17). It has been suggested that the disappearance of ER $\alpha$ at the time of implantation may disturb the expression pattern of proteins that regulate endometrial receptivity.

Despite the existence of a plethora of studies on the role of these steroid hormones and their receptors at the endometrial level, knowledge around their protein expression and tissue distribution during the implantation window (days 0-5) in humans remains limited. One of the main reasons for this lack of knowledge is that participants in such studies are required to undergo endometrial biopsy, which obviously affects endometrial receptivity and subsequently the success of in vitro fertilisation (IVF). Therefore, it is not feasible to carry out a study in women undergoing IVF, since the procedure will have an adverse effect on the outcome. The patient population of the present study consisted of women undergoing ovarian stimulation for egg donation.

In this study the following question was addressed: Can morphological and functional markers be used to evaluate the changes in the endometrium during implantation in women undergoing IVF?

In this study we investigated whether morphological and functional markers (i.e. ER and PR) can be used to evaluate the changes in the endometrium during implantation in women undergoing IVF.

\section{Materials and methods}

Study population and design. The study was conducted at the 1st Dept. of OB-GYN, Centre for Human Reproduction of the Aristotle University of Thessaloniki, 'Papageorgiou' General Hospital and the 'Biogenesis' Assisted Reproduction Centre, (both in Thessaloniki, Greece). The participants recruited for this prospective study included 15 oocyte donors (age range, 25-32 years; mean age, 28.9 \pm 2.89 ) undergoing IVF treatment. The inclusion criteria were white race, no uterine-ovarian pathology, age $<35$ years and no prior known medical pathology. All donors had undergone extensive preoperative work-up, which included common blood tests, karyotyping, specific test for cystic fibrosis and pap smear. All donors were non-smokers and had given their informed consent (NP: A 13032 15/7/10). Informed consent was written, and patients agreed to the use of their samples in scientific research.
Participants underwent ovarian stimulation with gonadotrophin-releasing hormone antagonist and recombinant follicle-stimulating hormone (18-20). Endometrial aspiration biopsy was performed using a Z-Sampler (Gynétics) on the day of oocyte retrieval and 5 days later (Fig. 1A).

Immunohistochemistry. Endometrial histology was evaluated blindly, using the Noyes criteria by a single specialized pathologist (20). The tissue was fixed in neutral buffered formalin $10 \%$ and followed the usual technical procedure for histological samples and embedding in paraffin blocks. Sections ( $3 \mu \mathrm{m}$ thickness) were sliced from the blocks placed on slides and then stained with hematoxylin and eosin for the evaluation of histologic characteristic. Immunohistochemistry was used to evaluate expression of ER $\alpha$ and PR-B, using monoclonal antibodies (ER: Clone 4f11, PR:clone 16+SAN27; Leica). Immunohistochemistry was performed on Ventana Benchmark XT automatic immunostainer (Ventana Medical Systems Inc.) using OptiView DAB IHC detection kit (Roche) as a detection method. As part of the automated service positive and negative controls (immunoglobulin $\mathrm{G}$ control) were tested simultaneously with the test slides (Fig. S1). The percentage of epithelial cell nuclei positive for ER $\alpha$ and PR-B receptors was recorded on days 0 and 5. Slide photos were captured using a x10-magnification lens on a Leica DMi1 Inverted Microscope (Leica Microsystems, Inc.), with all scale bars set to $0.25 \mathrm{~mm}$.

Bioinformatic analysis. GeneMANIA (http://genemania. org/), a user-friendly web interface that provides large datasets to perform analyses for gene and protein interactions and prioritise genes for functional assays. Using this software, the relationship between ER and PR with 43 previously identified genes (21) involved with unexplained infertility (UIF) and recurrent implantation failure (RIF) were used to generate PPI networks using GeneMANIA.

Statistical analysis. Statistical analysis was performed using the SPSS version 23 (IBM Corp.). The data were non-parametric (Shapiro-Wilk normality test $\mathrm{P}<0.005$ ), and as such, the Wilcoxon signed-rank, Mann-Whitney U and Fisher's exact tests were used for analysis. A two-tailed $\mathrm{P}<0.05$ was considered to indicate a statistically significant difference. Sample stratification (for ER staining only) was performed for ages $( \pm 30$ years old) and to determine whether there was differential gene expression between the two days (yes, no).

\section{Results}

Differential expression of steroid hormone receptors during the implantation window. Both ER $\alpha$ and PR-B were expressed abundantly on both days ( 0 and 5; Fig. 1B). The ER $\alpha$ nodal staining percentage on day 0 was age-related, with patients aged $<30$ years showing $100 \%$ staining and those aged $>30$ years showing 90\% staining (Mann-Whitney U test; $\mathrm{P}=0.014$; Fig. 2A).

Both steroid hormone receptors showed significant variation between days 0 and 5, both in the nodal and stromal preparations. According to Wilcoxon signed-rank test; for ER (nodes \% and stromal \%) Day 0/5, P=0.0001; for PR (nodes \% and stromal \%) Day $0 / 5, \mathrm{P}=0.0001$ and $\mathrm{P}=0.035$, respectively; 


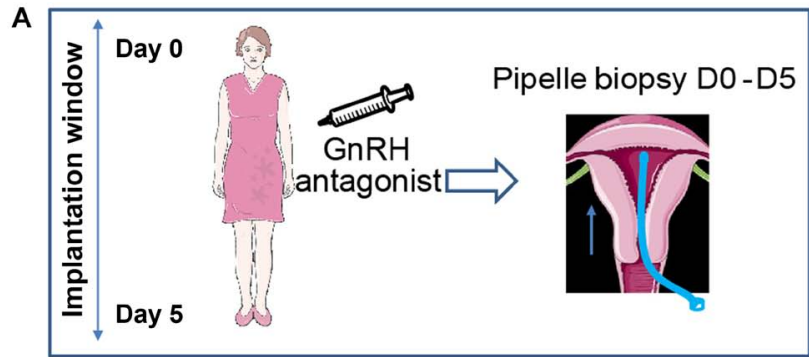

B

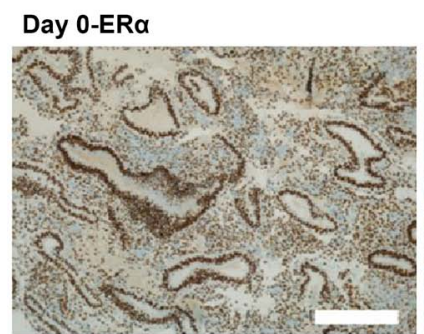

Day 0-PR-B

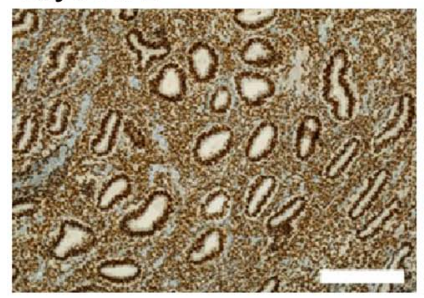

Day 5-ERa

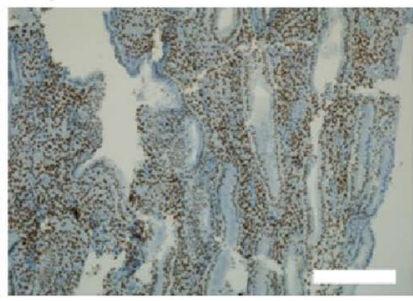

Day 5-PR-B

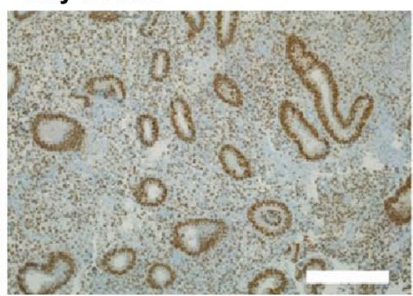

Figure 1. Biopsy removal and immunohistochemistry for ER $\alpha$ and PR-B (A) Schematic diagram of the biopsy procedure. (B) Examples of immunohistochemistry for ER $\alpha$ and PR-B. Scale bar, $0.25 \mathrm{~mm}$. ER $\alpha$, estrogen receptor $\alpha$; PR-B, progesterone receptor-B; $\mathrm{D}$, day; GnRH, gonadotropin releasing hormone.

for ER (Grade nodes and stromal) Day $0 / 5, \mathrm{P}=0.0001$; and for PR (Grade nodes and stromal) Day $0 / 5, \mathrm{P}=0.0001$ and $\mathrm{P}=0.016$, respectively (Fig. 2B and C; Table I).

Involvement of $E R$ and $P R-B$ in endometrial gene networks: An in-silico analysis. In a recent meritorious study, microarray datasets collected during the time of human uterine receptivity and implantation were compared to the transcriptome signature of women with unexplained infertility (UIF) and recurrent implantation failure (RIF) (21). In that study, the authors have identified 24 and 21 shared differentially expressed genes (DEGs) between the transcriptome of women with UIF and RIF and those of normal endometrial receptivity samples (Table II) (21).

In view of the differential expression of ER and PR-B during the implantation window, their potential involvement was investigated further by studying potential interactions between the common genes for UIF and RIF using GeneMANIA software. The previously identified UIF genes (21) that potentially interact with ER are as follows: Thyrotropin releasing hormone (TRH), TRH receptor (TRHR), GLI family zinc finger 1, matrix metallopeptidase 26 (MMP26), retinol binding protein 4, serpin family A member 1, MMP7, catenin $\alpha 2$, hyaluronan binding protein 2, collagen type IX $\alpha 1$ (Fig. 3A). PR-B appears to interact with the following genes: Chromosome 20 open reading frame 103 , calpain 6 , thrombospondin 4 , leucine rich repeat containing 17 , periostin, collagen type IV $\alpha 6$ chain,
A

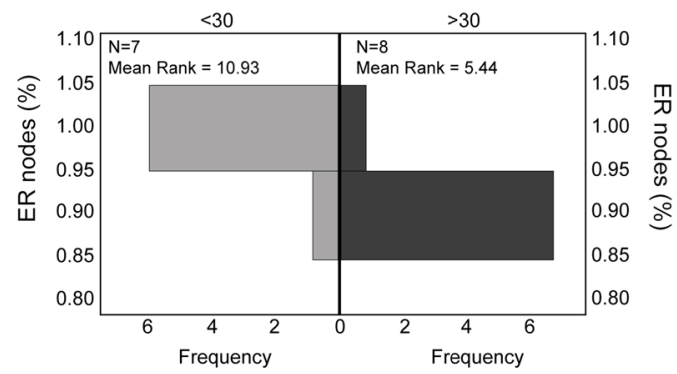

B

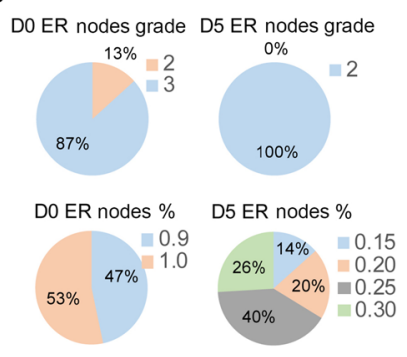

D0 ER stromal grade D5 ER stromal grade

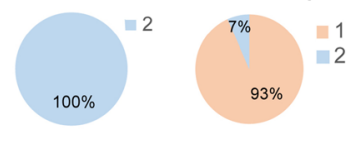

D0 ER stromal \% D5 ER stromal \%

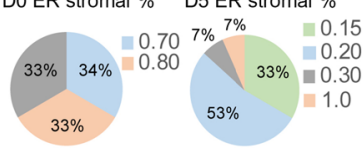

C D0 PR nodes grade D5 PR nodes grade

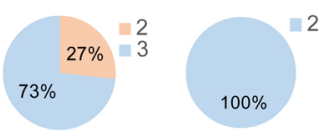

D0 PR nodes \% $\quad$ D5 PR nodes \%

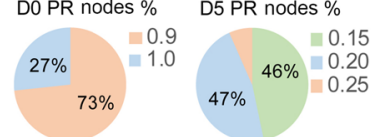

D0 PR stromal grade D5 PR stromal grade

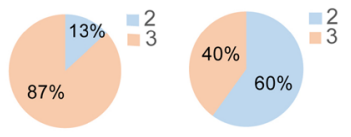

D0 PR stromal \% D5 PR stromal \%

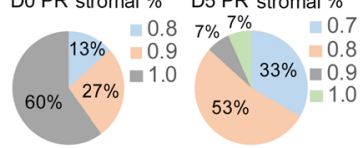

Figure 2. Differences in the expression grade and location of ER $\alpha$ and PR-B. (A) Frequency of ER expression stratified by age. ER $\alpha$ and PR-B expression on days 0 and 5. Pie charts of histopathology results for positive nuclei percentage and receptor grade per location for both (B) ER $\alpha$ and (C) PR-B. $\mathrm{ER} \alpha$, estrogen receptor; PR-B, progesterone receptor-B; D, day.

TRH, TRHR, nidogen 2, MMP7, MMP26, oviductal glycoprotein 1 (OVGP1), Jun dimerization protein 2, endothelin converting enzyme like 1, insulin like growth factor binding protein 1 (IGFBP1), Kruppel-like factor 9 (Fig. 3B).

In the case of previously identified RIF overlapping genes (21), potential interactions with ER include: Prostaglandin E receptor 3, Wilms tumor 1 (WT1), progestogen-associated endometrial protein (PAEP), odd-skipped related transcription factor 2, progesterone receptor, nidogen 1 , nuclear factor I/A, splicing factor 1 (SF1; Fig. 4A). PR-B interacts with the following genes: Clusterin, solute carrier family 9 member A3, OVGP1, PAEP, superoxide dismutase 3, extracellular, ribonucleotide reductase regulatory TP53 inducible subunit M2B, ephrin B2, hydroxysteroid 17- $\beta$ dehydrogenase 2 (HSD17B2), kallikrein related peptidase 3 , and IGFBP1 (Fig. 4B).

\section{Discussion}

Successful implantation following IVF is a complex procedure that is very much dependent on the fertilized egg's progression into a blastocyst, synchronized with the differentiation of the endometrium $(1,2)$. This 'implantation window' initiates a molecular dialogue of sorts that has not yet been fully clarified (1-4).

The aim of the present study was to elucidate a small part of this dialogue. These results, in combination with the 
Table I. Descriptive statistics of immunohistochemical analysis.

\begin{tabular}{lccccc}
\hline Parameter & $\mathrm{N}$ & Minimum & Maximum & Mean & SDEV \\
\hline Age (years) & 15 & 25 & 32 & 28.93 & 2.89 \\
A, Day 0 & & & & \\
ER nodal grade & 15 & 2.00 & 3.00 & 2.87 & 0.35 \\
ER stromal grade & 15 & 2.00 & 2.00 & 2.00 & 0.00 \\
ER nodal \% & 15 & 0.90 & 1.00 & 0.95 & 0.05 \\
ER stromal \% & 15 & 0.70 & 0.90 & 0.80 & 0.08 \\
PR nodal grade & 15 & 2.00 & 3.00 & 2.73 & 0.05 \\
PR stromal grade & 15 & 2.00 & 3.00 & 2.87 & 0.35 \\
PR nodal \% & 15 & 0.90 & 1.00 & 0.93 & 0.05 \\
PR stromal \% & 15 & 0.80 & 1.00 & 0.95 & 0.07 \\
B, Day 5 & & & & 1.00 & 0.00 \\
ER nodal grade & 15 & 1.00 & 1.00 & 1.07 & 0.26 \\
ER stromal grade & 15 & 1.00 & 2.00 & 0.24 & 0.05 \\
ER nodal \% & 15 & 0.15 & 0.30 & 0.24 & 0.21 \\
ER stromal \% & 15 & 0.15 & 1.00 & 1.00 & 0.00 \\
PR nodal grade & 15 & 1.00 & 3.00 & 2.40 & 0.51 \\
PR stromal grade & 15 & 2.00 & 0.25 & 0.18 & 0.03 \\
PR nodal \% & 15 & 0.15 & 1.00 & 0.89 & 0.06 \\
PR stromal \% & 15 & 0.70 & & &
\end{tabular}

ER, estrogen receptor; $\mathrm{PR}$, progesterone receptor; $\mathrm{SDEV}$, mean $\pm \mathrm{SD}$.

number of ERs and PRs, play an important role in the success of IVF, since their expression causes a series of paracrine and autocrine signals, which through adhesion molecule processes ultimately lead to the successful adhesion and penetration of the endometrium by blastocysts (22). As far as permeability is concerned, the effect of ovarian steroids on the uterus is achieved through their receptors (23). Immunohistochemistry results for ER receptors showed a significant reduction in D5, as compared to D0, while an equally significant increase in the PR receptors was observed on the same days. Nodal ER and PR receptors with a strong presence on day 0 showed a very limited presence on day 5, while only PR receptors were strongly represented in the stroma. Estrogens in the follicular phase prepare the endometrium for the action of progesterone in the subsequent secretory phase of the cycle (24). Having stratified our samples into two age-groups ( $<30$ and $>30$ years), it was found that the ER receptor nodal staining percentage on day 0 was age-related, with patients aged $<30$ years showing $100 \%$ staining and those aged $>30$ years showing $90 \%$ staining. This was consistent with potential age-related complications associated with maternity and successful pregnancy. Progesterone is another determining factor in the creation of the implantation window and the maintenance of pregnancy. The stromal cells differentiate into progesterone-responsive peristaltic cells during the perforation process, which is characterized by morphological changes (25). In the present study, changes in the expression of PR-B were observed between days 0 and 5 . This was consistent with a study showing that stimulation of the endometrium with ganirelix acetate (a GnRH antagonist) and gonadotropins led to the increase of PR-B gene expression at the time of embryo transfer (26). Of note, in the same study it was only the expression of PR-B that changed, while PR-A, the other splice isoform of the PR, was undetectable. It should be noted that, in addition to the two well studied variants of PR-A and -B, other splicing isoforms have also been detected including PR-C and PR-M (27). Moreover, it is now well accepted that both steroids can activate membrane-bound receptors acting in a non-genomic manner $(28,29)$. Future studies should also concentrate on elucidating the expression of these receptors during the implantation window. Finally, evidence of a potential crosstalk between these receptors and genes implicated in RIF and UIF during the implantation window was provided herein, using data previously generated (21). This is of interest, given that these genes are involved in key physiological processes, such as the regulation of the protein activation cascade, complement activation, humoral immune response, acute inflammatory response or protein processing in the case of the gene cluster, which is common in RIF. One of the most interesting interactions of both ER and PR is with TRH and TRHR in UIF. Previous studies have corroborated these in silico findings in other in vitro or in vivo systems. For example, $17 \beta$-estradiol (E2) was found to modulate the prolactin secretion induced by TRH in a female anterior pituitary primary cell culture. This response was mediated by a membrane-ER, but this finding provided an insight into a potential crosstalk (30). Similarly, E2 appears to inhibit TRH expression in the hypothalamic paraventricular nucleus of female rats (31). Similarly, TRHR immunoreactivity in the myometrium of cynomolgus macaques was increased when they were treated with conjugated equine estrogens alone or in 
Table II. Full names of genes studied in silico including genes that have been identified from the previous referenced study (21).

\section{Official}

gene symbol

Name

\begin{tabular}{|c|c|}
\hline POSTN & Periostin, osteoblast specific factor \\
\hline RBP4 & Retinol binding protein 4 , plasma \\
\hline MMP26 & Matrix metallopeptidase 26 \\
\hline WT1 & Wilms tumor 1 \\
\hline LRRC17 & Leucine rich repeat containing 17 \\
\hline OSR2 & Odd-skipped related transcription factor 2 \\
\hline HABP2 & Hyaluronan binding protein 2 \\
\hline HSD17B2 & Hydroxysteroid (17- $\beta$ ) dehydrogenase 2 \\
\hline PTGER3 & Prostaglandin E receptor 3 \\
\hline SOD3 & Superoxide dismutase 3 , extracellular \\
\hline PAEP & Progestogen-associated endometrial protein \\
\hline THBS4 & Thrombospondin 4 \\
\hline EFNB2 & Ephrin-B2 \\
\hline TRHR & Thyrotropin-releasing hormone receptor \\
\hline ECEL1 & Endothelin converting enzyme-like 1 \\
\hline GLI1 & GLI family zinc finger 1 \\
\hline MMP7 & $\begin{array}{l}\text { Matrix metallopeptidase } 7 \\
\text { (matrilysin, uterine) }\end{array}$ \\
\hline COL9A1 & Collagen type IX, $\alpha 1$ \\
\hline SERPINA1 & $\begin{array}{l}\text { Serpin peptidase inhibitor, clade A, } \\
\text { member } 1\end{array}$ \\
\hline CTNNA2 & Catenin (cadherin-associated protein), $\alpha 2$ \\
\hline KLK3 & Kallikrein-related peptidase 3 \\
\hline JDP2 & Jun dimerization protein 2 \\
\hline IGFBP1 & Insulin-like growth factor binding protein 1 \\
\hline KLF9 & Kruppel-like factor 9 \\
\hline C20orf103 & Chromosome 20 open reading frame 103 \\
\hline NID2 & Nidogen 2 (osteonidogen) \\
\hline CAPN6 & Calpain 6 \\
\hline OVGP1 & Oviductal glycoprotein $1,120 \mathrm{kDa}$ \\
\hline NID1 & Nidogen 1 \\
\hline SLC9A3 & $\begin{array}{l}\text { Solute carrier family } 9 \text { (sodium/hydrogen } \\
\text { exchanger), member } 3\end{array}$ \\
\hline PGR & Progesterone receptor \\
\hline SF1 & Splicing factor 1 \\
\hline CLU & Clusterin \\
\hline COL4A6 & Collage type IV $\alpha 6$ chain \\
\hline RRM2B & $\begin{array}{l}\text { Ribonucleotide reductase regulatory TP53 } \\
\text { inducible subunit M2B }\end{array}$ \\
\hline $\mathrm{TRH}$ & Thyrotropin-releasing hormone \\
\hline NFIA & Nuclear factor I/A \\
\hline
\end{tabular}

combination with medroxyprogesterone acetate (32). Another common pathway that estrogen and progesterone appear to modulate is that of MMP7. Again, previous studies have corroborated this interaction. There has been an association between cellular and molecular responses in the rat mammary gland and E2, including MMP7 and MMP9 (33). When female sheep pups were treated with $\mathrm{P} 4$, it led to a reduced expression of MMP7. Moreover, P4 inhibited uterine gland development in the uterus of a neonatal mouse; a process that involved the downregulation of MMP7 (34). Endometriotic cells have been found to contain the full complement of steroidogenic genes such as SF1 and WT-1, which can influence the transcription of steroidogenic genes necessary for E2 synthesis in endometriosis (35). A similar interplay between ER-SF1-WT1 was produced as interactions under RIF conditions. On the other hand, P4 inhibited the stimulatory effect of E2 on the expression of oviductin in the cervix of rhesus macaques (36). In addition, HSD17B2 expression in endometrial epithelial cells was found to be regulated by downstream molecules of progesterone (37).

Finally, we have shown using qRT-PCR that patients that were E-Cadherin-positive between days 0 and 5 were also all PR Grade 3. The small sample of this study clearly limits its scientific value, particularly with regards to very low gene expression, and lack of any statistical strength. We appreciate that this is a limitation of the current study. However, it should be noted that endometrial sampling at Day 5 is considered an invasive procedure and a cause of some discomfort to the individual, so it is very hard to recruit large numbers. Despite close follow-ups of the oocyte recipients, matching the morphological-structural changes of the donor endometria and the IVF result was not feasible, due to the anonymous nature of the oocyte donation procedure. It should be noted that the present the present study is limited to young women (due to better quality of oocytes and lower incidence of trisomy 21) and future studies should aim to test whether the present findings would hold true in other age ranges, such as women $>35$ years old.

Another limitation of the present study is that immunohistochemistry is less quantitative than western blotting. Performing this analysis using a housekeeping protein as a loading control, such as GAPDH or $\beta$-actin, would have been useful. Alternatively, ELISA or a gene expression assessment of both receptors using RT-qPCR could have been conducted. However, due to ethical restrictions, sufficient tissue for protein extraction could not be obtained in order to pursue this further.

As mentioned, synchronization between blastocyst development and the acquisition of endometrial receptivity is a prerequisite for the success of IVF, a process that appears to be dependent on a number of different events at the hormonal and cellular levels. In this study, novel evidence of differential expression and potential involvement of two key steroid hormone receptors in this process was provided; namely, in women undergoing treatment during an oocyte donation program. The present results, combined with those of in silico analyses, suggested that the changes in ER and PR expression and cellular distribution are crucial events that can impact implantation. This should be investigated further in studies with a larger population, which should further validate the original findings using alternative, more quantitative approaches, and further explore changes between D0-5 in a 'non-biased' way through RNAseq or proteomic analysis instead. Expanding our knowledge on this field beyond the two steroid hormone receptors described herein, would augment our understanding of the signalling mechanisms implicated in infertility, and potentially provide novel therapeutic targets. It would have 

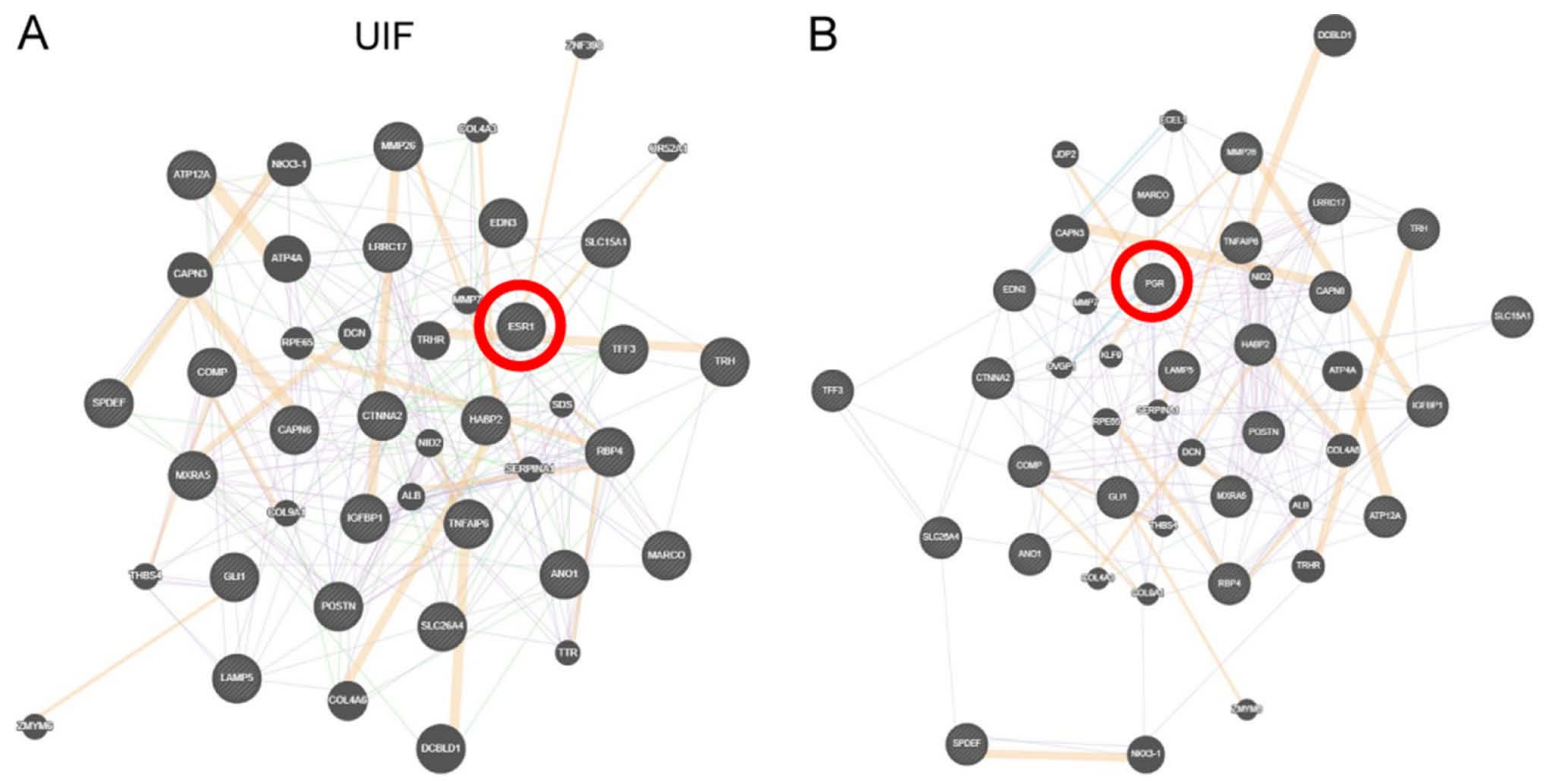

Figure 3. Predictive interactions of ESRI and PFR during UIF. Network annotation of previously identified genes involved in UIF with (A) estrogen receptor alpha (ESR1 in red circle) and (B) progesterone receptor (PGR in red circle). ESRI, estrogen receptor $\alpha$; PFR, progesterone receptor; UIF, unexplained infertility.

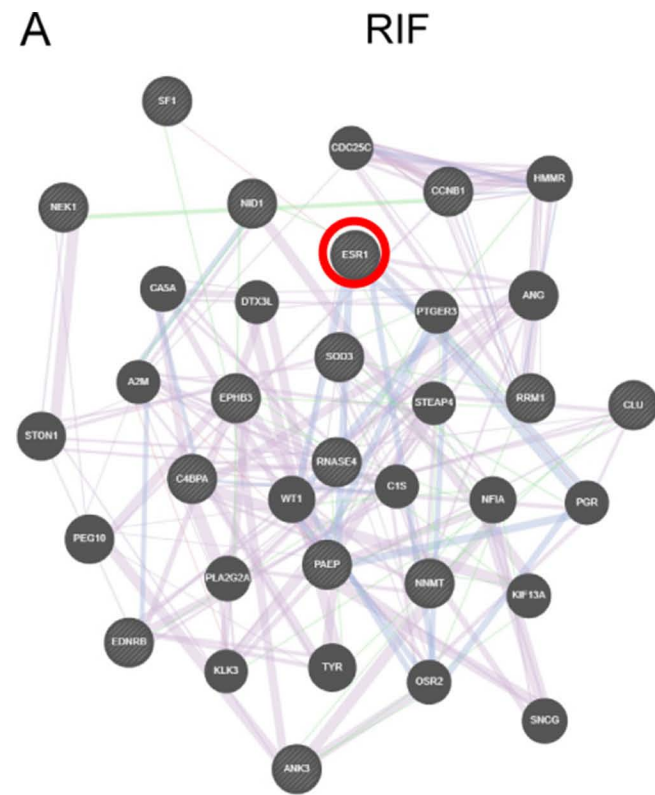

\section{B}

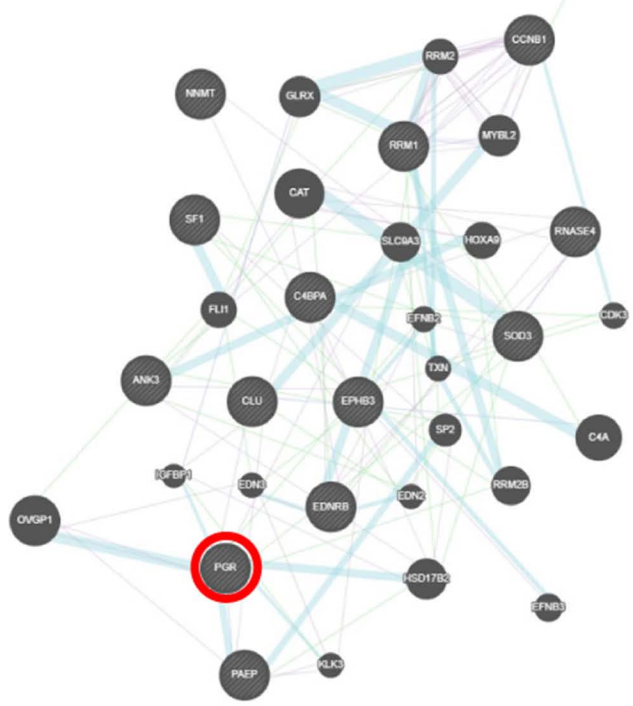

Figure 4. Network annotation of previously identified genes involved in RIF with (A) ESR1 (red circle) and (B) PGR (red circle). RIF, recurrent implantation failure; ESR1, estrogen receptor $\alpha$; PFR, progesterone receptor.

been useful to investigate the downstream signalling as well. However, for this to happen we would need to generate primary cell cultures from the biopsies. This was impossible due to the small size of the study. There are no commercially available cell lines to mimic this pharmacological milieu. We mention this under limitations in our discussion. It is for the very reason that we embarked on bioinformatic analysis to we provide novel evidence for a potential crosstalk of these receptors during the implantation window with genes that are implicated in RIF and UIF.

In conclusion, successful implantation implies synchronization between a blastocyst and the endometrium, which undergoes structural and functional remodelling. It was shown herein that both ER-a and PR-B were expressed abundantly on days 0 and 5 , showing significant variation in the nodal and stromal preparations. Age appeared to be a critical factor, since ER-a nodal staining showed higher values in the age group of oocyte donors $<30$ years old. Therefore, focusing on the functional characteristics of the endometrium will provide a better insight into successful embryo implantation, thus improving IVF results.

\section{Acknowledgements}

Not applicable. 


\section{Funding}

No funding was received.

\section{Availability of data and materials}

The datasets used and/or analyzed during the current study are available from the corresponding author on reasonable request.

\section{Authors' contributions}

EKa, EP, BT and GP conceived the current study. EK1, PK and EKa performed the experiments. EK1, PK, Eka and GP performed in silico, bioinformatics and statistical analyses. $\mathrm{EKa}, \mathrm{EP}, \mathrm{BT}$ and GP performed the investigation provided funding and materials. EKl and PK integrated the data and created figures. EKl, PK, Eka and GP wrote the original draft. writing review and editing, EKl, EKa, EP, BT and GP reviewed and edited the manuscript. EK1 and GP supervised the study. All authors read and approved the final manuscript.

\section{Ethics approval and consent to participate}

The present study was approved by the Committee for Medical Ethics and Deontology, School of Medicine, Aristotle University of Thessaloniki (approval no. A 13032 15/7/10). Written informed consent was obtained from patients prior to enrolment.

\section{Patient consent for publication}

Consent for publication was obtained from all patients.

\section{Competing interests}

The authors declare that they have no competing interests.

\section{References}

1. Krüssel JS, Bielfeld P, Polan ML and Simón C: Regulation of embryonic implantation. Eur J Obstet Gynecol Reprod Biol 110 (Suppl 1): S2-S9, 2003.

2. Teh WT, McBain J and Rogers P: What is the contribution of embryo-endometrial asynchrony to implantation failure? J Assist Reprod Genet 33: 1419-1430, 2016.

3. Sharma A and Kumar P: Understanding implantation window, a crucial phenomenon. J Hum Reprod Sci 5: 2-6, 2012.

4. Fox C and Lessey BA: Signaling between embryo and endometrium: Normal implantation. In: Recurrent Implantation Failure: Etiologies and Clinical Management, pp1-19, 2018.

5. Young SL: Oestrogen and progesterone action on endometrium: A translational approach to understanding endometrial receptivity. Reprod Biomed Online 27: 497-505, 2013.

6. Kumar R, Zakharov MN, Khan SH, Miki R, Jang H, Toraldo G, Singh R, Bhasin S and Jasuja R: The dynamic structure of the estrogen receptor. J Amino Acids 2011: 812540, 2011.

7. Sharkey AM and Smith SK: The endometrium as a cause of implantation failure. Best Pract Res Clin Obstet Gynaecol 17 : 289-307, 2003

8. Schwartz MA: Integrins and extracellular matrix in mechanotransduction. Cold Spring Harb Perspect Biol 2: a005066, 2010.

9. Arnaout MA, Goodman SL and Xiong JP: Structure and mechanics of integrin-based cell adhesion. Curr Opin Cell Biol 19: 495-507, 2007.

10. Wang $\mathbf{J}$ and Armant DR: Integrin-mediated adhesion and signaling during blastocyst implantation. Cells Tissues Organs 172: 190-201, 2002 .
11. Basak S, Dhar R and Das C: Steroids modulate the expression of alpha4 integrin in mouse blastocysts and uterus during implantation. Biol Reprod 66: 1784-1789, 2002.

12. Stemmler MP: Cadherins in development and cancer. Mol Biosyst 4: 835-850, 2008.

13. Gumbiner BM: Cell adhesion: the molecular basis of tissue architecture and morphogenesis. Cell 84: 345-357, 1996.

14. Poncelet C, Leblanc M, Walker-Combrouze F, Soriano D, Feldmann G, Madelenat P, Scoazec JY and Daraï E: Expression of cadherins and CD44 isoforms in human endometrium and peritoneal endometriosis. Acta Obstet Gynecol Scand 81: 195-203, 2002.

15. Jha RK, Titus S, Saxena D, Kumar PG and Laloraya M: Profiling of E-cadherin, beta-catenin and $\mathrm{Ca}(2+)$ in embryo-uterine interactions at implantation. FEBS Lett 580: 5653-5660, 2006.

16. Lessey BA, Killam AP, Metzger DA, Haney AF, Greene GL and McCarty KS Jr: Immunohistochemical analysis of human uterine estrogen and progesterone receptors throughout the menstrual cycle. J Clin Endocrinol Metab 67: 334-340, 1988.

17. Gregory CW, Wilson EM, Apparao KB, Lininger RA, Meyer WR, Kowalik A, Fritz MA and Lessey BA: Steroid receptor coactivator expression throughout the menstrual cycle in normal and abnormal endometrium. J Clin Endocrinol Metab 87: 2960-2966, 2002.

18. Papanikolaou EG, Bourgain C, Kolibianakis E, Tournaye H and Devroey P: Steroid receptor expression in late follicular phase endometrium in GnRH antagonist IVF cycles is already altered, indicating initiation of early luteal phase transformation in the absence of secretory changes. Hum Reprod 20: 1541-1547, 2005.

19. Papanikolaou EG, D'haeseleer E, Verheyen G, Van de Velde H, Camus M, Van Steirteghem A, Devroey P and Tournaye H: Live birth rate is significantly higher after blastocyst transfer than after cleavage-stage embryo transfer when at least four embryos are available on day 3 of embryo culture. A randomized prospective study. Hum Reprod 20: 3198-3203, 2005.

20. Noyes RW, Hertig AT and Rock J: Dating the endometrial biopsy. Am J Obstet Gynecol 122: 262-263, 1975.

21. Herington JL, Guo Y, Reese J and Paria BC: Gene profiling the window of implantation: Microarray analyses from human and rodent models. J Reprod Heal Med 2 (Suppl 2): S19-S25, 2016.

22. Fox C, Morin S, Jeong JW, Scott RT Jr and Lessey BA: Local and systemic factors and implantation: What is the evidence? Fertil Steril 105: 873-884, 2016.

23. Carpenter KD and Korach KS: Potential biological functions emerging from the different estrogen receptors. Ann N Y Acad Sci 1092: 361-373, 2006.

24. Kodaman PH and Taylor HS: Hormonal regulation of implantation. Obstet Gynecol Clin North Am 31: 745-66, ix, 2004.

25. Dunn CL, Kelly RW and Critchley HO: Decidualization of the human endometrial stromal cell: An enigmatic transformation. Reprod Biomed Online 7: 151-161, 2003.

26. Detti L, Saed GM, Fletcher NM, Kruger ML, Brossoit M and Diamond MP: Endometrial morphology and modulation of hormone receptors during ovarian stimulation for assisted reproductive technology cycles. Fertil Steril 95: 1037-1041, 2011.

27. Zachariades E, Foster H, Goumenou A, Thomas P, Rand-Weaver $\mathrm{M}$ and Karteris E: Expression of membrane and nuclear progesterone receptors in two human placental choriocarcinoma cell lines (JEG-3 and BeWo): Effects of syncytialization. Int J Mol Med 27: 767-774, 2011.

28. Foster H, Reynolds A, Stenbeck G, Dong J, Thomas P and Karteris E: Internalisation of membrane progesterone receptor-alpha after treatment with progesterone: Potential involvement of a clathrin-dependent pathway. Mol Med Rep 3: 27-35, 2010

29. Karteris E, Zervou S, Pang Y, Dong J, Hillhouse EW, Randeva HS and Thomas P: Progesterone signaling in human myometrium through two novel membrane $\mathrm{G}$ protein-coupled receptors: Potential role in functional progesterone withdrawal at term. Mol Endocrinol 20: 1519-1534, 2006.

30. Sosa LD, Gutiérrez S, Petiti JP, Palmeri CM, Mascanfroni ID, Soaje M, De Paul AL and Torres AI: $17 \beta$-Estradiol modulates the prolactin secretion induced by TRH through membrane estrogen receptors via PI3K/Akt in female rat anterior pituitary cell culture. Am J Physiol Endocrinol Metab 302: E1189-E1197, 2012.

31. Uribe RM, Zacarias M, Corkidi G, Cisneros M, Charli JL and Joseph-Bravo P: $17 \beta$-Oestradiol indirectly inhibits thyrotrophin-releasing hormone expression in the hypothalamic paraventricular nucleus of female rats and blunts thyroid axis response to cold exposure. J Neuroendocrinol 21: 439-448, 2009. 
32. Hulchiy M, Zhang H, Cline JM, Hirschberg AL and Sahlin L: Receptors for thyrotropin-releasing hormone, thyroid-stimulating hormone, and thyroid hormones in the macaque uterus: Effects of long-term sex hormone treatment. Menopause 19: 1253-1259, 2012.

33. Ding L, Zhao Y, Warren CL, Sullivan R, Eliceiri KW and Shull JD: Association of cellular and molecular responses in the rat mammary gland to $17 \beta$-estradiol with susceptibility to mammary cancer. BMC Cancer 13: 573, 2013.

34. Filant J, Zhou H and Spencer T: Progesterone inhibits uterine gland development in the neonatal mouse uterus. Biol Reprod 86: $146,1-9,2012$.

35. Attar E, Tokunaga H, Imir G, Yilmaz MB, Redwine D, Putman M, Gurates B, Attar R, Yaegashi N, Hales DB and Bulun SE: Prostaglandin E2 via steroidogenic factor-1 coordinately regulates transcription of steroidogenic genes necessary for estrogen synthesis in endometriosis. J Clin Endocrinol Metab 94: 623-631, 2009.
36. Slayden OD, Friason FKE, Bond KR and Mishler EC: Hormonal regulation of oviductal glycoprotein 1 (OVGP1; MUC9) in the rhesus macaque cervix. J Med Primatol 47: 362-370, 2018.

37. Cheng YH, Imir A, Suzuki T, Fenkci V, Yilmaz B, Sasano H and Bulun SE: SP1 and SP3 mediate progesterone-dependent induction of the 17beta hydroxysteroid dehydrogenase type 2 gene in human endometrium. Biol Reprod 75: 605-614, 2006.

This work is licensed under a Creative Commons Attribution-NonCommercial-NoDerivatives 4.0 International (CC BY-NC-ND 4.0) License. 